\title{
Panel: The Identity and Dynamics of MIS
}

\author{
Tor J. Larsen and Linda Levine \\ Norwegian School of Management, Norway \\ Software Engineering Insitute, Carnegie Mellon University, U.S.A. \\ e-mail: Tor.J.Larsen@BI.NO
}

\begin{abstract}
In this panel, we address the identity and dynamics of MIS, including myths and taboos in the history of the field, interdisciplinary identities, intradisciplinary perspectives, and empirics on coherence and change in the discipline. Panelists are Frank Land, London School of Economics, UK Michael D. Myers, University of Auckland Business School, NZ Robert Zmud, Michael F. Price College of Business, University of Oklahoma, OK and Linda Levine, Software Engineering Institute, Carnegie Mellon University, PA. Panel Moderator and Point of Contact:Tor J. Larsen
\end{abstract}

\section{Introduction}

No end appears to be in sight for the now familiar and longstanding discussions on the status of the field of Management Information Systems (MIS) ${ }^{1}$-its identity and its value, with respect to its role as a field, within the university, and in relation to industry practice.This ongoing debate and relentless self-examination reveals two persistent themes. The first focuses on coherence in MIS and in framing questions such as: Does MIS have a core and overarching theory? A cumulative tradition? Are other disciplines referencing MIS. The second theme revolves around the matter of rigor versus relevance, which is also occasionally expressed as a debate between academic and practical concerns-where a further refinement focuses on degrees of purity in the use of research methods. If we are to come to grips with these issues we

${ }^{1}$ Different labels are used to refer to the field, for example: Information Technology (IT), Information Communication Technology (ICT), Information Systems (IS), Management Information Systems (MIS), and Information Management (IM). Each term has its proponents; however, the terms are often used interchangeably. For the sake of clarity and consistency, we use the term Management Information Systems. 
need to consider some of the myths, taboos and misconceptions which have grown up within our discourse.

Further refinement on the nature of MIS has examined its core and sub areas. One approach distinguishes between the internalist view and the externalist view. The internalist view builds on Kuhn's notion of a dominant paradigm in the tradition of normal science, which is interspersed with periods of revolution. This dominant paradigm takes the form of an overarching theory, which is subscribed to by a research community. The externalist view treats a discipline as a "complex network of interacting researchers whose ideas may stem from a number of disciplines who therefore form an intellectual community". Many characterize this network as a "fragmented adhocracy." Another example of the externalist view is expressed through Porra's notion of "colonial systems." Vessey et al. demonstrate that there is considerable diversity in MIS research in the topics addressed, research approaches employed, reference disciplines used, and levels of analysis. Their findings dispute the internalist view.

Benbasat and Zmud argue that a definition of the IS artifact can serve as the platform for defining appropriate MIS research. Ives, Parks, Porra, and Silva present a strong counter argument. They advocate the field of MIS research is best seen as a "colonial system" where colonies have strong inner ties but loose outer connections. They assert that the glue in MIS is a common interest in information technology and information systems. Similarly, King describes the discipline of MIS as driven by "...a shared interest in a phenomenal event-the rise and consequences of radical improvement in information technology." ... and any, "attempt to build a longstanding academic field on a phenomenon, especially a revolutionary phenomenon, will fail". As Fitzgerald aptly observes: "In IS, we stand with our backs to the technology, the computer, the machine or whatever, and look outward towards the world at large.".

We agree with our colleagues in MIS who argue that "letting a thousand flowers bloom" is a necessary prerequisite for developing theories and expanding our knowledge. The continuous surge of new technologies and fads also contributes to this abundance. However, the current state of a thousand flowers does not absolve us of the need to examine patterns in the composition of MIS and its areas of work.

In this panel, we address the identity and dynamics of MIS, including myths and taboos in the history of the field, interdisciplinary identities, intradisciplinary perspectives, and empirics on coherence and change in the discipline.

\section{Myths, Taboos and Misconceptions in the IS Domain Frank Land.}

It is just over 50 years since computers began to be used as practical tools for business and administration, and about 40 years since MIS began to establish it self as a distinct academic discipline. In that time the discipline has grown to become a major component of the academic calendar. As a new discipline, often driven by a rapidly developing technology, it has sought to define its subject matter and its boundaries. That debate has been ongoing and even today fills the pages of some of its best journals. But in some senses MIS is a flawed discipline. In the $\mathbf{5 0}$ or so years of its existence the discipline has accumulated an array of myths, taboos and 
misconceptions. Some are deeply embedded in the mindsets of our peers. Some are transient, but have important impacts on what research gets carried out in a particular time. Many stem from not fully understood borrowings from our reference disciplines. Some take the form of tacit assumptions widely held, but because they are not articulated, they are also not tested. Of course all disciplines have these problems.

In this panel discussion I want to point to a selection of the myth, taboos, and misconceptions which disfigure our disciplines and hope that by highlighting some we can, as a community, begin to be aware of what we need to do.

\section{Interdisciplinary Identities: MIS and Reference Disciplines Michael D. Myers,}

In his presentation Michael will present a review of the history of the IS field and show how the IS field has developed its own unique identity, a unique research perspective and its own research tradition. He will argue that the time has come for IS researchers to stop seeing other fields as "reference disciplines" (i.e. fields which we look up to for theories, methods and exemplars of good research). Rather, IS researchers should see the IS field as one amongst others. However, this new found identity does not mean that IS researchers should cut themselves off from other related disciplines. On the contrary, IS researchers should be encouraged to conduct interdisciplinary work with scholars from other fields - but as equal partners in the important work of knowledge creation .

\section{Intradisciplinary Perspective Robert Zmud,}

Benbasat and Zmud articulated an intensively debated position on the desirability of establishing boundaries for the MIS discipline - boundaries that are intimately defined in terms of the IT artifact and its immediate context. Here, this position will be both clarified and extended. While this refined position maintains the earlierstated position, it more explicitly recognizes that such a boundary invariably shifts to reflect concomitant changes in the nature of the phenomena subsumed within the boundary and the emergence of new phenomena. The issues raised by the emergence of new phenomena are particularly challenging, especially as it relates to disciplinary boundaries for an interdisciplinary field such as MIS. Of central importance is the necessity to distinguish whether 'new phenomena' are in fact 'new' or instead variants of phenomena already subsumed within existing scholarly disciplines. The implications of such challenges to the MIS discipline are examined and interpreted within the refined position.

\section{Empirics: Coherence and Change in the Discipline Linda Levine}

The research questions we pose here ask: what themes or ideas represent the center of MIS or its zones of coherence - or is diversity and fragmentation the rule? And will the center or zones change over time? Within MIS research, is there evidence of theory building that contributes to a cumulative research tradition? Using a co-word 
analysis approach-to analyze the patterns in discourse by measuring the association strengths of terms representative of relevant publications-the researchers found 62 specific centers of coherence. The data documented a high degree of change in centers of coherence over time. Evidence of theory building was extremely weak. A cumulative research tradition remains elusive. MIS centers of coherence change over time- -we think, partly in response to practical pressures. We suggest that MIS opens a richer and more difficult debate on its theory, practice, and identity as a discipline in the $21^{\text {st }}$ century university.

\section{Biographies}

Frank Land has spent almost his entire career working with IS/IT. After graduating from the LSE in 1950 he worked for 16 years with the pioneering business computer offshoot of the large British food and catering company J. Lyons and company. He was appointed Professor of Systems Analysis in 1982 and later joined the London Business School as Professor of Information Management. On retirement, he returned to the LSE as an Emeritus Professor. Frank received the AIS LEO Award, an AIS Fellowship and an IFIP Outstanding Service Award. He is currently working in the field of Knowledge Management and researching the relevance of Complexity Theory to understanding aspects of the IS phenomenon.

Tor J. Larsen received his Ph.D. in Management Information Systems (MIS) from the University of Minnesota, U.S.A., 1989. Since then he has worked as associate professor at the Norwegian School of Management, Department of Leadership and Organizational Management. He has acted as its Head of Department since 2003. Dr. Larsen's publications are found in, for example, Information \& Management, Journal of MIS, and Information Systems Journal. His professional memberships include AIS, IFIP WG 8.2, and WG 8.6. His present research interests are innovation, diffusion, innovation outcome specification, MIS, and technology mediated learning.

Linda Levine is a senior member of the technical staff at the Software Engineering Institute. Her research focuses on acquisition of software intensive systems, agile software development, and diffusion of innovations. She holds a $\mathrm{PhD}$ from Carnegie Mellon University. Levine has over 60 publications in a wide range of journals. including: IEEE Software, Information Systems Journal, Michigan Telecommunications and Technology Law Review, and Scandinavian Journal of Information Systems. She is a member of the IEEE Computer Society, AIS, National Communication Association, and cofounder and vice chair of IFIP WG 8.6 on Diffusion, Transfer and Implementation of Information Technology.

Michael D. Myers is Professor of Information Systems and Associate Dean at the University of Auckland Business School. His research interests are in information systems development, qualitative research methods in information systems, and the social and organizational aspects of information technology. He has won Best Paper awards in MISQ and Information Technology \& People. Dr. Myers served as a Senior Editor of MISQ (2000-2005), as an Associate Editor of Information Systems 
Research (2000-2005). He currently serves as President of AIS and as Chair of the IFIP WG 8.2.

Robert Zmud is Professor and Michael F. Price Chair in MIS, Division of MIS, Michael F. Price College of Business, University of Oklahoma. His research interests focus on the organizational impacts of information technology and on the management, implementation and diffusion of information technology. He currently is a Senior Editor with Information Systems Research and MISQ Executive and he sits on the editorial boards of Management Science, Academy of Management Review and Information and Organization. He is a fellow of both AIS and DSI. He holds a Ph.D. from the University of Arizona and a M.S. from M.I.T. 